\title{
MODIFICAÇÃO DA SUPERFÍCIE DO RESÍDUO DE CASCA DE LARANJA PARA ADSORÇÃO DE CORANTES
}

\section{Gabriel Nery Nascimento ${ }^{1}$ e Suzana Modesto de Oliveira Brito ${ }^{2}$}

1. Bolsista PROBIC/CNPq, Graduando em Licenciatura em Química, Universidade Estadual de Feira de Santana, e-mail: eugabrielnery@ gmail.com

2. Orientador, Departamento de Exatas, Universidade Estadual de Feira de Santana, e-mail: $\underline{\text { smobrito@uefs.br }}$

PALAVRAS-CHAVE: adsorção; casca de laranja; azul de metileno.

\section{INTRODUÇÃO}

Diversas indústrias usam corantes na fabricação de seus produtos, principalmente as indústrias têxteis, curtumes, indústrias de papel, de alimentos, entre outras. Os corantes sintéticos são amplamente utilizados, por causa de suas vantagens em relação aos corantes naturais (Kharat, 2015). A produção anual de corantes sintéticos chega a 700000 toneladas/ano e cerca de 10 a $15 \%$ dos corantes utilizados pelas indústrias chegam aos efluentes (Kyzas, 2013). A remoção de corantes de forma economicamente viável permanece um problema importante. Os processos de adsorção, pela sua não especificidade, são os mais apropriados para purificação de efluentes, uma vez que são capazes de remover vários tipos de substâncias, em níveis que vão do mais concentrado até o traço. Como o custo deste processo é alto para tratamento de efluentes, a busca por materiais alternativos tem interessado os cientistas nos últimos anos.

O resíduo da laranja pode causar muitos problemas econômicos e ambientais devido principalmente à sua elevada fermentação, pois contém cerca de $86 \%$ (b.u) de água (Tripodo, 2004). O bagaço pode ser utilizado como aditivo na alimentação de ruminantes na forma de ensilagem ou ração peletizada, diminuindo assim o consumo de grãos para os animais e, consequentemente, os custos de alimentação. Segundo Ítavo et al. (2000), o valor nutricional do bagaço de laranja é semelhante ao dos demais grãos utilizados na alimentação dos animais, além de apresentar elevada digestibilidade, atribuída sobretudo ao seu alto teor de carboidratos solúveis e pectina; além do uso como ração animal, a indústria tem grande interesse em desenvolver novas aplicações para o bagaço da laranja, destacando-se a utilização deste material como adsorvente no tratamento de efluentes (FIORENTIN, 2015).

\section{MATERIAL E MÉTODOS OU METODOLOGIA}

Inicialmente foram preparadas as soluções-estoque de azul de metileno usando aproximadamente $0,5 \mathrm{~g}$ de corante diluído em água deionizada num balão volumétrico de $500 \mathrm{~mL}$ obtendo-se, assim, soluções com concentração aproximada de $1000 \mathrm{mg} / \mathrm{L}$. A partir das soluções-estoque, foram preparadas outras soluções com concentrações diferentes: 100, 200, 400, 600 e $800 \mathrm{mg} / \mathrm{L}$, as quais foram usadas para realizar os estudos cinéticos.

Para os ensaios de adsorção, construiu-se uma curva de calibração variando-se a concentração inicial das soluções de $100 \mathrm{mg} / \mathrm{L}$ de 2 a $10 \mathrm{mg} / \mathrm{L}$. As concentrações das soluções foram determinadas através de um espectrofotômetro Femto Plus UV/VIS no comprimento de onda, pré-definido por varredura, de $660 \mathrm{~nm}$ para o corante azul de metileno. 
As cascas de laranja foram obtidas nas cantinas da UEFS. Após aquisição o material foi cortado em pequenas fatias e exposto ao sol para retirar o excesso de água presente. Após exposição ao sol, o resíduo foi colocado em estufa Nova Ética 330D à $80^{\circ} \mathrm{C}$ até total dessecação, a fim de retirar a umidade presente. Por fim, o material dessecado foi triturado em um moinho de facas tipo Willye e lavado em água deionizada com auxilio um misturador automático Quimis®, sendo novamente seco em estufa. $O$ material foi peneirado para separação e ajuste de granulometria.

Para analisar a viabilidade da adsorção, foram feitos estudos de equilibrio, colocando-se aproximadamente $0,1 \mathrm{~g}$ das amostras em frascos individuais de $100 \mathrm{~mL}$ devidamente identificados, aos quais também foram adicionados $15 \mathrm{~mL}$ de cada uma das soluções preparadas nas diferentes concentrações. As misturas, nos frascos, foram colocadas sob agitação em banho metabólico durante $01,02,04,06,08$ e 24 horas à temperatura ambiente, e depois nas temperaturas de $40^{\circ} \mathrm{Ce} 70^{\circ} \mathrm{C}$.

Após 24 horas de agitação, as amostras foram filtradas e a concentração da solução de corante foi determinada usando um espectrofotômetro Femto 700 Plus UV/VIS a 660nm para o azul de metileno . A partir dos dados obtidos foi possível avaliar as concentrações das soluções depois da adsorção e, com esses dados, construir as respectivas isotermas de adsorção.

\section{RESULTADOS E/OU DISCUSSÃO}

\section{MICROSCOPIA ELETRÔNICA DE VARREDURA}

O material não apresentou uma estrutura porosa ao microscópio, mas o acesso aos grupos superficiais é fácil. A superfície da casca de laranja é plana, apresentando concavidades e reentrâncias na superfície, que podem funcionar como poros para a adsorção, facilitando o acesso aos grupos superficiais responsáveis pela adsorção. As imagens de MEV são mostradas na Figura 1.

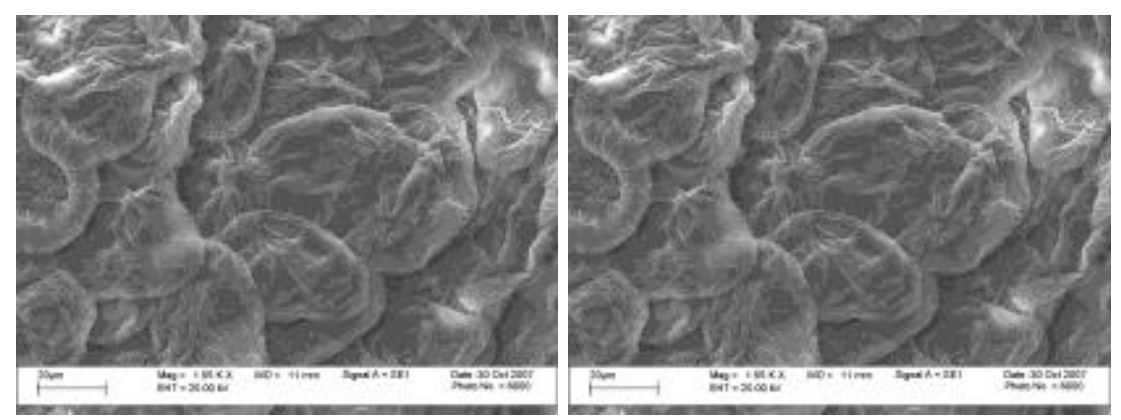

Figura 1 - Imagens de MEV da casca de laranja

\section{ANÁLISES TERMOGRAVIMÉTRICAS}

Os resultados mostraram que ocorre uma perda de massa em torno de $55^{\circ} \mathrm{C}$, que foi atribuída à perda de água do material. Os picos de perda de massa acima de $280^{\circ} \mathrm{C}$ foram atribuídos à decomposição térmica do material. A análise termogravimétrica demonstrou que a temperatura escolhida para a secagem do material não altera a estrutura do mesmo, assegurando que estamos realmente trabalhando com os resíduos não carbonizados. Desse modo, toda a capacidade de adsorção pode ser totalmente atribuída ao material em seu estado natural, com a superfície não tratada, e não a 
uma possível formação de carvão ativado ou a algum material carbonizado precursor de carvão ativado, formado durante o pré-tratamento.

ISOTERMAS DE ADSORÇÃO

Os modelos matemáticos mais utilizados para representar a adsorção em fase líquida são os de Langmuir e de Freundlich. A Isoterma de Adsorção de azul de metileno para a casca de laranja depois de 24 horas de agitação e temperatura ambiente é mostrada na Figura 1.

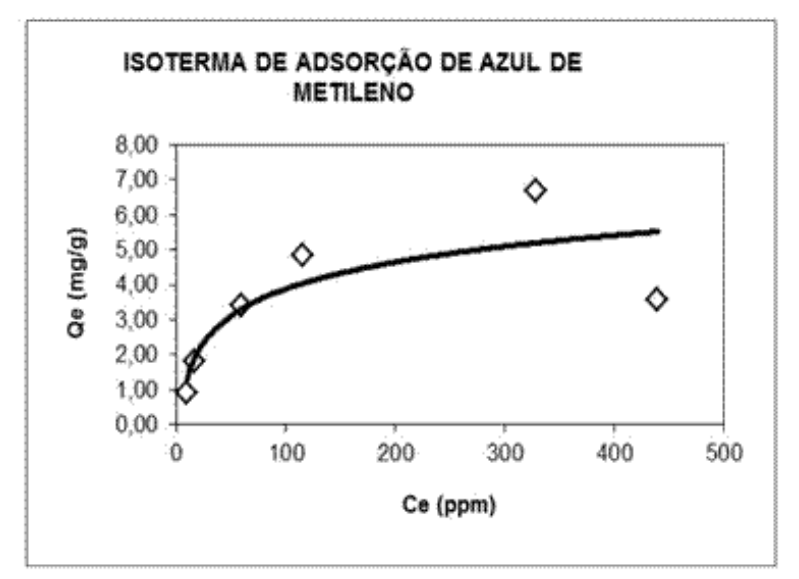

Figura 1 - Isoterma de adsorção de azul de metileno sobre casca de laranja a temperatura ambiente

Os resultados obtidos para os parâmetros de linearização segundo os modelos de Langmuir e Freundlich são mostrados na Tabela 1.

Tabela 1. Parâmetros das isotermas de Langmuir e Freundlich para adsorção sobre CL

\begin{tabular}{|c|c|c|c|c|c|c|}
\hline \multirow[t]{2}{*}{ Corantes } & \multicolumn{3}{|c|}{ Parâmetros de Langmuir } & \multicolumn{3}{|c|}{ Parâmetros de Freundlich } \\
\hline & $\begin{array}{c}\mathrm{Q}_{\max } \\
\left(\mathrm{mg} \cdot \mathrm{g}^{-1}\right)\end{array}$ & $\begin{array}{c}\mathrm{b} \\
\left(\mathrm{L} \cdot \mathrm{mg}^{-1}\right)\end{array}$ & $\mathrm{R}^{2 *}$ & $\begin{array}{c}\mathrm{K}_{\mathrm{F}} \\
\left(\mathrm{L} \cdot \mathrm{mg}^{-1}\right)\end{array}$ & $1 / \mathrm{n}$ & $\mathrm{R}^{2 *}$ \\
\hline Azul de Metileno & 4,42 & 0,098 & 0,87 & 1,93 & 0,404 & 0,76 \\
\hline
\end{tabular}

Considerando que o modelo de adsorção que mais se ajusta aos dados é o de Langmuir, foi possível calcular o $\Delta \mathrm{G}$ de adsorção a partir da constante de Langmuir. $\mathrm{O}$ valor de $\Delta \mathrm{G}$ encontrado foi de $-5754,87 \mathrm{~J}$, indicando um processo espontâneo.

Os diagramas de adsorção de azul de metileno sobre casca de laranja em função do tempo são mostrados na Figura 2. Observa-se que a adsorção é rápida no início e que o equilibrio é atingido em cerca de 250 minutos para a adsorção de azul de metileno. A capacidade de adsorção aumenta com o aumento da concentração inicial em toda faixa de concentrações estudada.

A cinética de adsorção foi estudada segundo os modelos de pseudo-primeira ordem e pseudosegunda ordem. O coeficiente de correlação obtido para o modelo de pseudo segunda ordem foi de 0,999 indicando que este modelo descreve bem a cinética de adsorção do corante sobre casca de laranja. A constante de velocidade calculada foi de $0,12 \mathrm{~g} / \mathrm{mg}$.min para a adsorção de azul de metileno. 


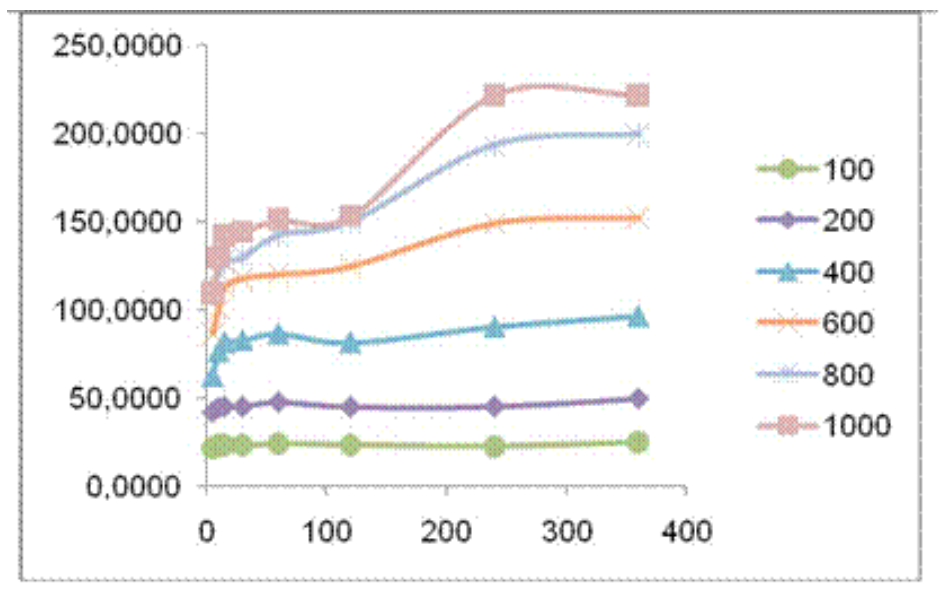

Figura 2. Efeito do tempo de contato na adsorção de azul de metileno

\section{CONCLUSÃO}

Os estudos sobre adsorção em casca de laranja ainda não estão concluídos, mas podemos prever que este material poderia ser um bom adsorvente para corantes básicos. A isoterma de Langmuir foi mais adequada para descrever o processo de adsorção e a cinética do processo pode ser descrita pelo modelo de pseudo-segunda ordem. $\mathrm{O}$ valor negativo da energia livre de Gibbs indica um processo espontâneo e energeticamente favorável.

\section{REFERÊNCIAS}

FIORENTIN, Leila D. et al. Determinação da cinética e das isotermas de secagem do bagaço da laranja. Acta Scientiarum. Technology, Maringá, v. 32, n. 2, p.147-152, 14 set. 2009. Anual. Disponível em: <file://C:/Users/Ana/Downloads/8242-38798-1-PB.pdf>. Acesso em: 31 mar. 2015. FIORENTIN, Leila D. et al. Sueli T. D. de Barros: Isotermas de sorção do resíduo agroindustrial bagaço de laranja. Revista Brasileira de Engenharia Agrícola e Ambiental, Campina Grande, v. 14, n. 6, p.653-659, 16 jan. 2009. Mensal. Disponível em: <http://www.scielo.br/pdf/rbeaa/v14n6/a12v14n6.pdf>. Acesso em: 31 mar. 2015.

G. Z. Kyzas, J. F. (2013). The change from past to future for adsorbent materials in treatment of dyeing wastewaters. Materials, 6, pp. 5131-5158. 